\title{
GLYCOSYLTRANSFERASES OF RAT BRAIN THAT MAKE CEREBROSIDES: SUBSTRATE SPECIFICITY, INHIBITORS, AND ABNORMAL PRODUCTS ${ }^{1}$
}

\author{
K. R. Warren, ${ }^{2}$ R. S. Misra, ${ }^{3}$ R. C. Arora ${ }^{4}$ and N. S. RadiN \\ Mental Health Research Institute and Department of Biological Chemistry, \\ University of Michigan, Ann Arbor, MI 48104, U.S.A.
}

(Received 9 April 1975. Accepted 3 November 1975)

\begin{abstract}
Brain homogenates from young rats were assayed for their ability to synthesize cerebrosides from radioactive UDP-galactose or UDP-glucose and ceramide. A comparison of galactose transfer with ceramides made from different 2-hydroxy acids showed that the shortest one tested $\left(\mathrm{C}_{7}\right)$ was by far the best acceptor, while the poorest contained 18 carbon atoms; longer fatty acids were better than $\mathrm{C}_{18}$. Glucosyltransferase, on the other hand, showed rather little chain length specificity or discrimination against hydroxy acid ceramides.

Synthetic compounds analogous in structure to ceramides were tested as inhibitors of the sugar transferases. Some were found to act as sugar acceptors themselves, particularly amides of DL-erythro-1phenyl-2-amino-1,3-propanediol. Some amides were good inhibitors of glucosyltransferase, particularly decanoyl norephedrine, decanoyl threo-1-phenyl-2-amino-1,3-propanediol and decenoyl phenylalaninol. The secondary amine analogous to the first of these, $N$-decyl norephedrine, was also very effective. No strong inhibitors of galactosyl transferase were found, although octanoyl D-threo-p-nitrophenylaminopropanediol showed promise $(42 \%$ inhibition at $0.3 \mathrm{~mm})$. Octanoyl phenylalaninol was nearly as good an inhibitor; the inhibition appeared only after a lag period.

It is suggested that the glucosyltransferase inhibitors might be useful in therapy of Gaucher's disease, by reducing the degradative load normally falling on glucocerebrosidase.
\end{abstract}

BRAIN contains glycosyltransferases which have the ability to form gluco- and galactocerebroside from the corresponding uridine nucleotide sugars and ceramide (Morell \& RAdin, 1969; Basu et al, 1968, 1971). The galactosyltransferase shows a marked preference for ceramides made from 2-hydroxy fatty acids, while the glucosyltransferase utilizes the hydroxy and nonhydroxy ceramides with roughly equal ability (SHAH, 1971; MoRell et al., 1970). This report presents details of the relative effectiveness of the enzymes with ceramides made from fatty acids of different chain lengths, with and without a D- or

\footnotetext{
${ }^{1}$ This work was supported by grants NS-03192 and GB 36735 from the United States Public Health Service and National Science Foundation.

${ }^{2}$ Postdoctoral trainee, Mental Health Research Institute, supported by grant MH-07417 from the National Institute of Mental Health. Present address: Department of Cellular Physiology, Walter Reed Army Institute of Research, Washington, DC 20012, U.S.A.

${ }^{3}$ Present address: Meyer L. Prentis Cancer Center, Detroit, MI 48201, U.S.A.

${ }^{4}$ Present address: Department of Biochemistry, The Chicago Medical School, Chicago, IL 60612, U.S.A.

Abbreviations used: Fatty acids are described digitally by chain length and number of double bonds (e.g.: 10:0 is decanoic acid). The letter $h$ in front of the abbreviation indicates the presence of a 2-hydroxy group. PAPD is 1-phenyl-2-amino-1,3-propanediol. Ceramide is the fatty acid amide of sphingenine.
}

L-hydroxyl group. (The D-configuration is the natural one in hydroxy cerebrosides.)

The primary purpose of this study was to search for effective inhibitors of the enzymes in an effort to control the metabolism of the glycolipids. In particular, it seemed possible that one might be able to ameliorate Krabbe's and Gaucher's diseases by slowing cerebroside biosynthesis in patients by means of suitable inhibitors. In these genetic disorders, hydrolysis of the two cerebrosides is seriously impaired and it is plausible to attempt reducing the load placed on the hydrolases by inhibiting cerebroside synthesis. This hypothesis could be examined by producing a model form of the genetic disorders in rats by means of hydrolase inhibitors-an attempt now under trial-and then correcting the disorders with synthetase inhibitors.

In the course of testing potential inhibitors, we found that some of the compounds acted as acceptors of the sugar moieties, forming abnormal cerebrosides.

\section{MATERIALS AND METHODS}

\section{Stereochemistry of substrates and inhibitors}

Sphingolipids have as their backbone the amino glycol, sphingosine (sphingenine), in which the $\mathrm{C}-2$ and $\mathrm{C}-3$ carbon atoms have the $\mathrm{D}$-configuration. We have made a large assortment of related compounds in which a small aliphatic group or a phenyl group replaces the long aliphatic chain of sphingenine. In some instances the hydroxyl group on the $\mathrm{C}-1$ or $\mathrm{C}-3$ position has been omitted. Some of 
the basic structures are shown here:
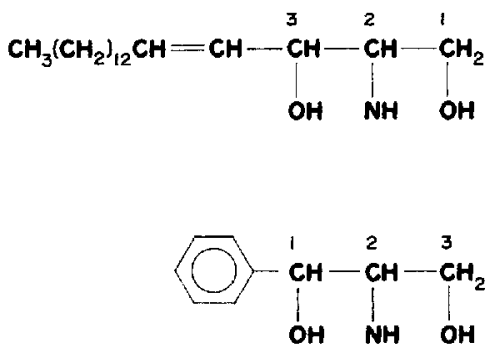<smiles>NC(CO)C(O)c1ccccc1</smiles><smiles>NC(CO)Cc1ccccc1</smiles><smiles>CC(N)C(O)c1ccccc1</smiles>

In some cases we used the DL-form rather than the $D$-form. In others the benzene ring possessed a nitro group in the para position. Note that the bend in the backbone of sphingenine produced by the trans double bond is partially mimicked by the bend introduced by the benzene ring. The rule for numbering carbon atoms requires that the phenyl derivatives be numbered differently than in sphingenine, as shown above, but in our previous papers we have used the same system for both to emphasize the steric relationships. The nitrogen atoms are shown with incomplete substituents to indicate the presence in our compounds of a carboxylic acid or an n-alkyl group.

\section{Synthesis of substrates and inhibitors}

Scveral amino alcohols were obtained as gifts (ARORA \& RADIN, 1972a). Norisoephedrine (D-threo-1-phenyl-2amino-1-propanol) was from ICN-K \& K Laboratories, Cleveland, OH. DL-2-Methylphenylalanine was from ICN Pharmaceuticals, at the same address. Nervonic acid was a gift from Dr. K. K. Carroll and trans-2-decenoic acid was from Research Organic/Inorganic Chemical Corp., Belleville, NJ. Most of the other reagents were from Aldrich Chemical Co., Milwaukee, WI.

Some of the compounds were prepared for other studies (HyUN et al., 1975; Arora et al,, 1973). In the case of the hydroxy acid ceramides, the starting material was DLhydroxy acid (prepared by bromination and hydrolysis of fatty acids) which was used to acylate natural (D) sphingosine. The resultant $\mathrm{DD}$ - and $\mathrm{LD}$-isomers were separated by chromatography on silica gel columns, the former coming out just after the latter as expected from the TLC separ-
D-erythro-sphingenine

\author{
D-erythro-1-phenyl-2-omino-1, 3-propanediol \\ (D-erythro-PAPD)
}

D-threo-PAPD

\section{D-1-phenyl-2-amino-3-propanol}

(D-phenylalaninol)

\section{D-erythro-I-phenyl-2-omino-I-propanol \\ (D-norephedrine)}

ations. The solvent used was $2-5 \%$ isopropanol in chloroform, depending on the fatty acid chain length.

Decenoic acid amides were synthesized via the $N$-hydroxy succinimide 2-decenoate ester (LAPIDOT et al., 1967). One of the amides was converted to the 2,3-epoxy derivative by refluxing $0.91 \mathrm{~g}$ decenoyl norephedrine $(3 \mathrm{mmol})$ with $0.67 \mathrm{~g}$ of $85 \%$ pure $m$-chloroperoxybenzoic acid $(3.3 \mathrm{mmol})$ in $10 \mathrm{ml}$ dichloroethane for $8 \mathrm{~h}$. The solution was washed with $\mathrm{NaOH}$ and water, evaporated to dryness and the residue triturated with hexane to produce $0.70 \mathrm{~g}$ $\left(73 \%\right.$ of theory) of crystals melting at $75-6^{\circ} \mathrm{C}$. The mixed m.p. with the starting material was $65-70^{\circ} \mathrm{C}$ and the original amide's m.p. was $92-3^{\circ} \mathrm{C}$. Curiously, the epoxy compound showed the same $R_{F}$ as the original amide $(0.71$ with chloroform-methanol-HOAc, 90:2:8) but it could be differentiated from the original compound because spraying with an epoxide indicator (OEsch et al., 1971) yielded a positive reaction. The elemental analysis, NMR data and i.r. spectrum confirmed the oxirane structure and absence of the trans double bond of the original amide.

Phenylalanine and 2-methylphenylalanine were reduced to the corresponding alcohols with sodium bis(2-methoxyethoxy)aluminum hydride ('Redal", Aldrich Chemical Co.). The amino acid was dried in a desiccator, then $4.64 \mathrm{~g}$ $(28 \mathrm{mmol})$ were added to a reflux system together with $25 \mathrm{ml}$ of dry benzene. Under nitrogen, $31 \mathrm{ml}$ of reducing agent (112 mmal) were added and the suspension was refluxed $3 \mathrm{~h}$. The resultant solution was cooled, $25 \mathrm{ml}$ of $40 \%$ aqueous $\mathrm{NaOH}$ were added slowly, the mixture was saturated with $\mathrm{NaCl}$ and the benzene layer was removed. The aqueous layer was extracted with $7 \times 50 \mathrm{ml}$ ether and the organic layers were pooled and evaporated to a small 
volume. Addition of benzene and cooling yielded $2.47 \mathrm{~g}$ of crystalline phenylalaninol ( $58 \%$ of theory). TLC of the product revealed a ninhydrin-positive spot corresponding to L-phenylalaninol from Fluka AG, Switzerland, together with a trace spot just above the amino alcohol (TLC solvent: chloroform-methanol-water-29\% ammonia 280:70:6:1). A charring spray showed the same two spots. In the case of 2-methylphenylalanine the yield was somewhat lower.

\section{Enzyme assays}

The enzyme source was brain from 16-day-old rats of the Sprague-Dawley strain, and the assay procedure was carried out as described before (BRENKERT \& RADIN, 1972; RADIN, 1972). The incubation medium, slightly modified, contained $0.1 \mathrm{M}$-Tris- $\mathrm{HCl}, \mathrm{pH} 7.4,15 \mathrm{~mm}-\mathrm{MgCl}_{2}, 2 \mathrm{~mm}$ EDTA, $1 \mathrm{~mm}$-dithioerythritol and $0.16 \mathrm{~mm}$-UDP-galactose or -glucose labelled in the sugar moiety. In the case of UDP-Glc, 2 mM-ATP was also included. Each assay tube contained $1 \mathrm{mg}$ of lyophilized brain homogenate or $0.5 \mathrm{mg}$ of acetone-washed lyophilized microsomes in a total volume of $0.2 \mathrm{ml}$. Where an inhibitor was to be tested, the compound was added to the incubation tube in solution and solvent removed before addition of the other assay components.

In most assays, the radioactive cerebroside was isolated by solvent partitioning, but in some cases the lipids were separated by TLC and the radioactive products located by exposure to $\mathrm{X}$-ray films. The radioactive powder was removed from the plate by scraping into glass scintillation vials, and the silica gel was dissolved by a modification of the method of SHAw et al. (1971). The powder was moistened with $0.4 \mathrm{ml}$ water, $0.3 \mathrm{ml}$ of concentrated $\mathrm{HF}$ was added, the vial was shaken on a gyrotory platform and $10 \mathrm{~m}$ l of scintillation solvent was added $(100 \mathrm{ml}$ Triton $\mathrm{X}-100+1.2 \mathrm{~g}$ PPO $+80 \mathrm{mg}$ dimethylPOPOP $+300 \mathrm{ml}$ xylene). One might expect this use of glass vials with $\mathrm{HF}$ to destroy the vials, but we found that they could be reused after simple washing.

The enzyme reactions were found to proceed at a constant rate for $90 \mathrm{~min}$ and the rates were proportional to the amount of enzyme used (within the range used). When galactosyltransferase was assayed, $0.2 \mathrm{mg}$ of a mixture of hydroxy ceramides (derived from cerebrosides) was added as sugar acceptor. In the case of glucosyliransferase, $0.2 \mathrm{mg}$ of mixed nonhydroxy ceramides was used for whole brain incubations and $0.05 \mathrm{mg}$ for microsomes, since the higher substrate concentration yielded slightly lower activities with microsomes.

The data reported are the average values from triplicate determinations made simultaneously. In some instances, where the activities seemed particularly interesting or unexpected, the assays were repeated once or twice more on different days with different batches of enzyme; the degree of inhibition observed with such repeated assays could differ by $5 \%$. In interpreting the significance of a result, one should compare the values obtained with homologs of different chain length or with a different level of substrate.

\section{RESULTS}

\section{Substrate specificity of galactosyltransferase}

In a comparison of the effectiveness of ceramides containing different hydroxy acids (Table 1), it was found that the best acceptor was the shortest one tested, made from $\mathrm{D}-h 7: 0$. The poorest one was the one made from D- $h 18: 0$. The $h 7: 0$ ceramide was about 7-times more effective than the natural mixture, which contained $h 24: 0, h 23: 0, h 22: 0, h 18: 0$ and $h 24: 1$ as the major components. As noted before (MORELL \& RADIN, 1969), the non-hydroxy ceramides were very poor substrates. Of particular interest is the trend with increasing chain lengths above 18 carbons: the $h 22: 0$ and $h 24: 0$ ceramides were more effective than $h 18: 0$. A similar strong preference for unusually short fatty acid derivatives was reported for the brain enzyme which forms phosphatidyl inositol (BENJAMINS \& AGRANOFF, 1969).

In some cases the unnatural ceramides, made with L-hydroxy acids, were tested. L- $h 7: 0$ was $29^{\circ}$, as

Table 1. Galactosylation of Different ceramides

\begin{tabular}{lcc}
\hline Fatty acid & Cerebroside formed & (nmol/h per mg) \\
\hline D- $h 7: 0$ & 16.0 & \\
D- $h 10: 0$ & 7.4 & 9.7 \\
D- $h 14: 0$ & 2.3 & \\
D- $h 18: 0$ & 0.8 & 1.8 \\
D- $h 22: 0$ & 1.4 & \\
D- $h 24: 0$ & 1.7 & 3.6 \\
Mixed hydroxy & 2.3 & \\
L- $h 7: 0$ & 4.6 & 2.1 \\
L- $h 10: 0$ & & 0.93 \\
L- $h 22: 0$ & & 0.13 \\
10:0 & & 0.08 \\
18:0 & & 0.07 \\
$24: 0$ & & 0.16 \\
$24: 1$ & & \\
\hline
\end{tabular}

The data in the first column were obtained with $0.1 \mathrm{mg}$ of microsomal powder and $0.2 \mathrm{mg}$ of ceramide, incubated as in Methods. The data in the right-hand column were obtained similarly, but with $0.5 \mathrm{mg}$ microsomes and $0.05 \mathrm{mg}$ ceramide. In the case of $\mathrm{D}-h 7: 0$, the incubation was for only $60 \mathrm{~min}$. Galactosyltransferase activity without added ceramide was 0.10 $\mathrm{nmol} / \mathrm{h}$ per $\mathrm{mg}$. 
Table 2. Glucosylation of Different ceramides

\begin{tabular}{lc}
\hline \multicolumn{1}{c}{ Fatty acid } & Cerebroside formed (nmol/h per mg) \\
\hline $10: 0$ & 2.7 \\
$14: 0$ & 2.3 \\
$18: 0$ & 2.2 \\
$22: 0$ & 2.6 \\
$24: 0$ & 2.4 \\
$24: 1$ & 2.9 \\
D- $h 10: 0$ & 2.0 \\
D- $h 18: 0$ & 2.4 \\
L- $h 18: 0$ & 1.6 \\
Mixed nonhydroxy & 2.7 \\
Mixed hydroxy & 2.0 \\
\hline
\end{tabular}

Incubations were carried out with $0.5 \mathrm{mg}$ microsomal powder and $0.05 \mathrm{mg}$ ceramide as in Methods. Glucosyltransferase activity without added ceramide was $2.0 \mathrm{nmol} / \mathrm{h}$ per $\mathrm{mg}$.

active as the D-isomer, $L-h 10: 0$ was $21 \%$ as effective as $\mathrm{D}-h 10: 0$ and $\mathrm{L}-h 22: 0$ was $51 \%$ as effective as $\mathrm{D}-h 22: 0$.

The data in Table 1 were obtained from equal weights of the different ceramides, so the molar concentration was inversely related to the chain length. Thus one might attribute some of the observed differences to the differing molar concentrations. However, several studies of activity vs concentration showed that we were using levels of substrate that were close to saturating.

Examination of some of the radioactive products by TLC (chloroform-methanol-water $144: 25: 2.8$ ) and radioautography showed, when mixed hydroxy ceramides were used, that the primary products were a double band in the cerebroside region corresponding approximately to $h 24: 0$ and $h 18: 0$ cerebrosides. In addition there was a faint, diffuse band which could be due to short chain hydroxy cerebrosides (such as h10:0) and a band considerably below the hydroxy cerebroside region. This last band had been noticed in previous studies; it is stable to alkaline methanolysis and does not appear in incubations made with synthetic ceramides. Presumably it is derived from an impurity in the mixed ceramides. It amounts to about $15 \%$ of the total radioactivity in the chloroform layer produced in the partitioning assay, so the data obtained with mixed ceramides are all a little too high.

By means of radioautography it could be shown that the radioactive product formed from each hydroxy ceramide exhibited the expected $R_{F}$ and relative intensity expected from the radioactivity found in the chloroform layer. When DL- $h 24: 0$ ceramide was tested as substrate, the expected radioactive band was produced but there was also a slightly radioactive band that was faster moving ( $R_{F} 0.53$ vs 0.40$)$. While one might expect to see some of the unnatural isomeric cerebroside, formed from the L-isomer, the relative migration rate seems too fast (HAJRA et al., 1966).

\section{Substrate specificity of glucosyltransferase}

This enzyme, in striking contrast to the galactosyltransferase, exhibited rather little specificity with respect to the length of the fatty acid chain in the ceramide (Table 2). Both D- and L-hydroxy acid ceramides were utilized with similar efficiency.

Examination of the radioactive glucosides by thinlayer plate radioautography showed that the endogenous ceramides yielded a cluster of cerebrosides around 18:0 cerebroside, but each added ceramide yielded primarily the expected narrow radioactive band arising from that particular precursor. Thus the

TABLE 3. INHIBITION BY AMIDES OF 1-PHENYL-2-AMINO-PROPANEDIOL-1,3

\begin{tabular}{ccccc}
\hline $\begin{array}{c}\text { Aromatic } \\
\text { substituent }\end{array}$ & $\begin{array}{c}\text { Fatty } \\
\text { acid }\end{array}$ & $\begin{array}{c}\text { PAPD } \\
\text { configuration }\end{array}$ & $\begin{array}{c}\text { Galactose } \\
\text { transfer }\end{array}$ & $\begin{array}{c}\text { Glucose } \\
\text { transfer }\end{array}$ \\
\hline- & $10: 0$ & DL-Erythro & 5 & +39 \\
- & $10: 0$ & L-Threo & 10 & 44 \\
- & $10: 0$ & D-Threo & 6 & 32 \\
- & Cinnamoyl & DL-Erythro & 11 & - \\
$m$-Nitro & Br-2:0 & DL-Erythro & 21 & + \\
$p$-Amino & $10: 0$ & DL-Erythro & +7 & +8 \\
$p$-Decanoyl- & $18: 0$ & DL-Erythro & 2 & +27 \\
amido & $10: 0$ & D-Threo & +7 & + \\
$p$-Phenyl & $h 12: 0$ & L-Threo & +17 & +27 \\
\hline
\end{tabular}

Data shown are per cent inhibition of the control activity obtained without added inhibitor. A plus sign indicates a higher activity than the control. Incubations were carried out with $0.3 \mathrm{~mm}$ inhibitor and $1 \mathrm{mg}$ of brain powder as described in Methods. 
TABLE 4. AMIDES OF p-NITRO PAPD as INHIBITORS

\begin{tabular}{llcc}
\hline \multicolumn{1}{c}{$\begin{array}{c}\text { Fatty } \\
\text { acid }\end{array}$} & $\begin{array}{c}\text { PAPD } \\
\text { configuration }\end{array}$ & $\begin{array}{c}\text { Galactose } \\
\text { transfer }\end{array}$ & $\begin{array}{c}\text { Glucose } \\
\text { transfer }\end{array}$ \\
\hline $24: 0$ & D-Threo & +3 & 32 \\
$18: 0$ & D-Threo & 1 & 38 \\
$16: 0$ & D-Threo & 1 & 29 \\
$14: 0$ & D-Threo & +17 & 33 \\
$12: 0$ & D-Threo & +8 & $44(43)$ \\
$10: 0$ & D-Threo & 24 & 44 \\
$8: 0$ & D-Threo & $42(64)$ & $45(73)$ \\
$6: 0$ & D-Threo & 7 & 11 \\
$10: 1$ & D-Threo & $32(45)$ & $34(63)$ \\
Cinnamoyl & D-Threo & $27(32)$ & $16(31)$ \\
Dichloroacetyl & D-Threo & 5 & +2 \\
$2-$ Br $6: 0$ & D-Threo & 8 & 19 \\
h12:0 & D-Threo & 0 & 17 \\
$10: 0$ & DL-Erythro & 14 & 21 \\
$8: 0$ & DL-Erythro & 12 & 29 \\
$6: 0$ & DL-Erythro & 12 & 7 \\
Cinnamoyl & DL-Erythro & 3 & 21 \\
$8: 0$ & L-Threo & 10 & - \\
\hline
\end{tabular}

Incubations were carried out with $0.3 \mathrm{~mm}$ inhibitor and $1 \mathrm{mg}$ brain powder as in Methods. Data show per cent inhibition of control activity. Data in parentheses were obtained similarly but with only $0.02 \mathrm{mg}$ of ceramides as sugar acceptor.

data in Table 2 largely represent the true synthesis of the expected cerebrosides.

\section{Amides of PAPD as inhibitors of galactosyltransferase}

Relatively small effects were observed with these analogs of ceramide (Table 3). Decanoyl DL-erythroPAPD, which had been found to be a good inhibitor of cerebroside galactosidase (ARORA \& RADIN, 1972a), was essentially inert against the transferase. The best inhibitor in this series was the bromoacetyl amide, previously mentioned as an inhibitor of this enzyme (ARORA \& RADIN, 1972b). In that study the inhibitory effectiveness had been somewhat greater, possibly because microsomes had been used in the assay.

The last compound in the table, a ceramide analog made from a DL-hydroxy acid, seemed to stimulate galactose transfer. However, as noted later in this paper, some of the hydroxy acid amides acted as substrates themselves, more effectively than the natural hydroxy ceramides.

While bromoacetyl PAPD showed promise as an inhibitor, 2-bromophenylacetyl PAPD (which has a more reactive bromine atom) was virtually inert.
PAPD amides containing a p-nitro group showed promise and were studied in greater detail (Table 4). As with the natural substrates, chain length of the fatty acid was a significant factor and only the octanoyl derivative of D-threo-PAPD was a good inhibitor. Insertion of a double bond in the decanoyl derivative enhanced its effectiveness. The dichloroacetyl compound, the commercially useful antibiotic, chloramphenicol, was virtually inactive. Unlike the $h 12: 0$ amide listed in Table 3 , the $h 12: 0$ amide in Table 4 was quite inert.

In the experiments where low concentrations of ceramide substrate were used (data in parentheses), inhibitory action was enhanced, indicating that these substinces acted as competitive inhibitors.

Amides of phenylalaninol as inhibitors of galactosyltransferase

1-Phenyl-2-amino-3-propanol is an analog of sphingosine in which the secondary alcohol group is lacking so there can be no distinction between threo and erythro isomers. Amides of this material (Table 5) showed some promise as inhibitors, the cinnamoyl

TABLe 5. Amides of PHENylalaninol as inhibitors

\begin{tabular}{lccc}
\hline \multicolumn{1}{c}{ Fatty acid } & C-2 isomer & Galactose & Glucose \\
\hline $16: 0$ & L & 16 & 9 \\
$10: 0$ & L & $25(23)$ & $42(64)$ \\
$10: 1$ & L & 30 & 56 \\
$8: 0$ & L & $27(30)$ & $39(59)$ \\
$6: 0$ & L & 1 & 7 \\
Cinnamoyl & L & $38(53)$ & $33(56)$ \\
$10: 0$ & D & 0 & 39 \\
$10: 1$ & D & 27 & 57 \\
$10: 0$ & DL-2-Me & $24(56)$ & $56(72)$ \\
\hline
\end{tabular}

Data obtained with $1 \mathrm{mg}$ brain homogenate as in Methods. Data in parentheses indicate per cent inhibition produced with $1 / 10$ the regular amount of ceramide acceptor. 
TABLE 6. INHIBITION BY AMIDES OF 1-PHENYL-2-AMINO-1-PROPANOL

\begin{tabular}{llcl}
\hline $\begin{array}{c}\text { Fatty } \\
\text { acid }\end{array}$ & \multicolumn{1}{c}{ Isomer } & $\begin{array}{c}\text { Galactose } \\
\text { transfer }\end{array}$ & $\begin{array}{c}\text { Glucose } \\
\text { transfer }\end{array}$ \\
\hline $24: 0$ & DL-Erythro & +19 & 36 \\
$16: 0$ & DL-Erythro & +10 & $36(59)$ \\
$14: 0$ & DL-Erythro & 0 & $37(70)$ \\
$12: 0$ & DL-Erythro & 0 & $47(77)$ \\
$10: 0$ & DL-Erythro & $12(24)$ & $69(82)$ \\
$8: 0$ & DL-Erythro & - & 36 \\
$6: 0$ & DL-Erythro & 0 & 7 \\
$10: 1$ & DL-Erythro & 8 & $44(65)$ \\
Benzoyl & DL-Erythro & 11 & 24 \\
$2-$ Br $6: 0$ & DL-Erythro & 3 & 15 \\
$10: 0$ epoxy* & DL-Erythro & 8 & 54 \\
$12: 0$ & D-Threo & 5 & $47(53)$ \\
$10: 0$ & D-Threo & 5 & 43 \\
$8: 0$ & D-Threo & 6 & $31(52)$ \\
$10: 1$ & D-Threo & - & 33 \\
Cinnamoyl & D-Threo & 4 & $22(29)$ \\
\hline
\end{tabular}

Amides evaluated with $1 \mathrm{mg}$ of brain powder. See legends to other tables for details.

* This is the compound formed by epoxidation of 2-decenoyl norephedrine.

derivative being the best. Curiously, the 10:0 amide of the D-isomer was inert, while the $10: 1$ amide showed some activity. There is some sign also with the L-isomer that the unsaturated amide is more effective than the saturated one.

Unexpectedly, two of the compounds tested with a low level of substrate showed no improvement in inhibitory power, suggesting that they act noncompetitively. The others tested this way showed the expected competition with ceramide.

Amides of 1-phenyl-2-amino-1-propanol as galactosyltransferase inhibitors

This series of compounds is derived from norephedrine (the DL-erythro isomer) and norisoephedrine, a naturally occurring substance (D-threo). All the compounds tested (Table 6) were found to be virtually inert or slightly stimulatory. In the case of the latter amides, it is not likely that they acted as galactose acceptors since the amides do not possess a primary alcohol group. It seems from the negative findings here that the galactosyltransferase, when acting on the natural substrate, has a site which binds the primary alcohol group. However, there must be some recognition of the aromatic analog since a test of the decanoyl DL-erythro compound with a low concentration of ceramide produced appreciable inhibition, $24 \%$. We prepared $N$-decanoyl norephedrine containing a catechol group [(3,4-dihydroxyphenyl)propanolamine] in the hope that it might bind to the galactosyltransferase and then oxidize and bind to the enzyme irreversibly. The binding was apparently slight since it produced only $8 \%$ inhibition.

\section{Aliphatic amides and miscellaneous amides tested with galactosyltransferase}

Several aliphatic amino alcohols were acylated, generally with decanoic acid, but tests with the galactosyltransferase system showed only small effects (Table 7). Decanoyl 2-methyl-2-amino-1-propanol, which had proved to be a good stimulator of cerebroside galactosidase (ARORA \& RADIN, 1972c), produced no effect. The ceramide made with sphingosine and 2-bromostearic acid, an analog of hydroxy ceramide, showed slight inhibitory power. A compound not shown in this table, the decanoyl amide of 0 -aminophenyl- $\beta$-glucoside, produced $16 \%$ inhibition.

TABLE 7. EFFECT OF ALIPHATIC AMIDES ON CEREBROSIDE SYNTHFSIS

\begin{tabular}{|c|c|c|c|}
\hline $\begin{array}{l}\text { Fatty } \\
\text { acid }\end{array}$ & Amino alcohol & $\begin{array}{c}\text { Galactose } \\
\text { transfer }\end{array}$ & $\begin{array}{l}\text { Glucose } \\
\text { transfer }\end{array}$ \\
\hline $10: 0$ & . $\mathrm{CH}_{3} \mathrm{CH}(\mathrm{NH}) \mathrm{CH}_{2} \mathrm{OH}$ & 2 & 13 \\
\hline $10: 0$ & $\mathrm{CH}_{3} \mathrm{CH}_{2} \mathrm{CH}(\mathrm{NH}) \mathrm{CH}_{2} \mathrm{OH}$ & +2 & 15 \\
\hline $10: 0$ & $\mathrm{CH}_{3} \mathrm{CH}(\mathrm{OH}) \mathrm{CH}_{2} \mathrm{NH}$ & +9 & 25 \\
\hline $10: 0$ & $\mathrm{CH}_{2}(\mathrm{OH}) \mathrm{C}\left(\mathrm{CH}_{3}\right)(\mathrm{NH}) \mathrm{CH}_{2} \mathrm{OH}$ & +3 & 19 \\
\hline $10: 0$ & $\mathrm{CH}_{3} \mathrm{C}\left(\mathrm{CH}_{3}\right)(\mathrm{NH}) \mathrm{CH}_{2} \mathrm{OH}$ & 2 & 34 \\
\hline \multicolumn{4}{|l|}{ Phenyl- } \\
\hline $2-\operatorname{Br} 2: 0$ & $\mathrm{CH}_{3} \mathrm{C}\left(\mathrm{CH}_{3}\right)(\mathrm{NH}) \mathrm{CH}_{2} \mathrm{OH}$ & +5 & - \\
\hline $2-\mathrm{Br} \quad 18: 0$ & Sphingosine & 11 & 16 \\
\hline
\end{tabular}

Data values are in per cent inhibition or $(+)$ stimulation obtained with whole brain powder. 
Table 8. Secondary alKyl amines as inhibitors

\begin{tabular}{|c|c|c|c|c|}
\hline $\begin{array}{l}\text { Aromatic } \\
\text { substituent }\end{array}$ & Amino alcohol & Alkyl chain & $\begin{array}{c}\text { Galactose } \\
\text { transfer }\end{array}$ & $\begin{array}{l}\text { Glucose } \\
\text { transfer }\end{array}$ \\
\hline- & DL-Erythro-norephed. & $10: 0$ & +19 & 61 \\
\hline- & DL-Erythro-norephed. & $h 10: 0$ & 20 & $\ldots$ \\
\hline$\ldots$ & DL-Erythro-norephed. & $-\left(\mathrm{CH}_{2}\right)_{3} \mathrm{COOEt}$ & 1 & - \\
\hline- & DI-Erythro-norephed. & $-\left(\mathrm{CH}_{2}\right)_{3} \mathrm{COOH}$ & 6 & -- \\
\hline- & DL-Erythro-PAPD & $6: 0$ & 2 & 一 \\
\hline- & DL-Erythro-PAPD & $10: 0$ & +12 & 38 \\
\hline- & L-Threo-PAPD & $10: 0$ & +16 & 35 \\
\hline- & D-Threo-PAPD & $10: 0$ & +16 & 26 \\
\hline$p$-Nitro & DL-Erythro-PAPD & $10: 0$ & +19 & 32 \\
\hline$p$-Nitro & L-Threo-PAPD & $10: 0$ & +11 & 20 \\
\hline p-Nitro & D-Threo-PAPD & $10: 0$ & +14 & 33 \\
\hline p-Amino & DL-Erythro-PAPD & $10: 0$ & +17 & -- \\
\hline p-Decanoylamido & DL-Erythro-PAPD & $10: 0$ & +15 & 6 \\
\hline$\ldots$ & L-Threo-PAPD & $h 10: 0$ & +11 & 25 \\
\hline$p$-Nitro & D-Threo-PAPD & $h 10: 0$ & 9 & 25 \\
\hline$p$-Amino & D-Threo-PAPD & - & 10 & +18 \\
\hline-- & L-Threo-PAPD & - & 3 & +9 \\
\hline
\end{tabular}

The amines were tested with $1 \mathrm{mg}$ brain powder as enzyme source.

Secondary amines as inhibitors of yalactosyltransferase

Various amino alcohol analogs of sphingosine were alkylated, generally with 1-bromodecane or 1,2-epoxydecane (Table 8). Comparison with the analogous amides (Tables 3 and 4) shows that the amines were distinctly less active, indicating the importance to the enzyme of the amido arrangement. Indeed, the secondary amines were generally found to be stimulatory when the alkyl group was long enough. There was no correlation of the stimulations with the configuration of carbons 2 and 3 , so it seems likely that the effect was due to an interaction at a site other than the catalytic one.

Glucosyltransferase and amides of aromatic analogs of sphingosine

The structural requisites for inhibition of the glucosyltransferase were found to be much less restrictive than for the galactosyltransferase. Perhaps this is to be expected from the lower specificity of the glucose enzyme with respect to nonhydroxy and hydroxy ceramides, as well as the fatty acid chain length in the ceramide (Tables 1 and 2). However, there was marked sensitivity to the configuration of the C-1 carbon atom, which can be seen in Table 3 (amides of threo-PAPD were inhibitory while amides of erythroPAPD, with or without a para substituent, were stimulatory). There was also distinct sensitivity to the configuration of the $\mathrm{C}-2$ carbon, since the D-threo compound was twice as effective as the L-threo compound in the case of the octanoyl amide of nitroPAPD (Table 4). As noted below, it is likely that the stimulations were actually due to utilization of the amides as glucose acceptors.

Omitting the $\mathrm{C}-1$ hydroxyl group (Table 5) enhanced the inhibitory effect. Use of 2-decenoic acid instead of decanoic acid further enhanced the effect with both the $\mathrm{L}$ - and D-isomers. A low ceramide concentration also enhanced the effect, indicating that the amides acted as competitive inhibitors. Placing a methyl group on the $\mathrm{C}-2$ carbon atom increased the effectiveness of the decanoyl compound.

The best inhibitors of glucose transferase were obtained when the C-3 hydroxyl group was omitted (Table 6). Here there was a distinct chain length effect, with decanoic acid having the optimal length. In this series decenoic acid was inferior to decanoic acid. Further tests with different concentrations of $N$-decanoyl DL-norephedrine showed that maximal inhibition was attained at $0.6 \mathrm{~mm}(75 \%$ with $0.2 \mathrm{mg}$ ceramide as acceptor) and significant inhibition was still detectable at $0.05 \mathrm{~mm}$ inhibitor $(16 \%)$.

Insertion of an oxirane ring ('10:0 epoxy") did not greatly affect the inhibitory ability of decanoyl norephedrine. It is possible that this inhibitor might slowly form a covalent bond, such as an ester linkage, with a sensitive site in the glucosyltransferase.

Of the aliphatic amides tested (Table 7), the monohydroxy branched methyl compound showed the most promise. The 2-methyl group definitely enhanced the inhibition, a point that may also be true in the phenylalaninol series (Table 5).

\section{Glucosyltransferase inhibition by secondary amines}

Unlike the case with galactosyltransferase, this enzyme generally interacted with the reduced amides (alkyl amines) rather much like its interaction with the corresponding amides. For example, decanoyl norephedrine (Table 6) was an excellent inhibitor of the glucose enzyme and the $N$-decyl analog (line 1, Table 8) was also excellent. However, decanoyl erythroPAPD (Table 3) stimulated glucose transfer while $N$-decyl erythro-PAPD inhibited it (Table 8).

\section{Amides of PAPD as substrates}

As noted above, some of the amides, particularly those most closely resembling ceramide in structure, 
seemed to stimulate sugar transfer. A study of 2-hydroxy acid amides showed that almost all produced this effect with both sugar nucleotides. The effect was smaller when the $\mathrm{C}-1$ hydroxyl was omitted or inverted and the $\mathrm{C}-2$ carbon had the L-configuration.

Further tests in which the natural substrates were omitted showed that radioactive lipid was formed anyway when the analog was present. As noted with the natural substrates, galactosyltransferase acted far better with analogs made from hydroxy acids while glucosyltransferase acted approximately equally well with hydroxy and nonhydroxy acid amides.

Radioautographic analysis of TLC plates made with the radioactive products showed that the analogs produced glycosides migrating more slowly than the natural cerebrosides. For example, the use of microsomes incubated with mixed hydroxy ceramides and labelied UDP-gal yielded the usual double hydroxy cerebroside band arising from the $\mathrm{C}-18$ and $\mathrm{C}-24$ clusters $\left(R_{F} \quad 0.42\right.$ and 0.47 with chloroform-methanolwater 24:7:1). When the $h 14: 0$ amide of erythroPAPD was included in the incubation, a strong band with $R_{F} 0.30$ also appeared, corresponding to the region just below phosphatidyl ethanolamine. Curiously, despite the use of an amide made from a DLhydroxy acid, only a single radioactive spot appeared, in contrast to the double band we found with DL-hydroxy acid amides of sphingosine.

With both UDP-Glc and UDP-gal, the amount of radioactivity found in each spot was depressed by the presence of the second amide. That is, the natural ceramides competed with formation of the unnatural 'cerebrosides' and the ceramide analog competed with the formation of the natural cerebrosides. This mutual inhibition is consistent with the assumption that both amides competed for the same catalytic site on each sugar transferase. In all the experiments in which an aromatic analog was the sole added sugar acceptor, we found the unnatural substance to be a better acceptor than the mixture of ceramides ordinarily used as substrate.

From the data in Table 4, it is apparent that the glucosyltransferase rejects acyl PAPD as sugar acceptor when a nitro group is present on the benzene ring. Nevertheless the nitro compounds must bind to the enzyme since they acted as inhibitors.

\section{Parametric studies of the inhibitory effects}

The data reported thus far in this paper were obtained with a single inhibitor concentration and a single time point. Several of the most active substances were tested in greater detail.

Octanoyl D-threo-nitroPAPD, our best galactosyltransferase inhibitor, was found to give the same degree of inhibition at all time points up to $90 \mathrm{~min}$. This indicates that it acts by a simple, reversible combination with the enzyme. On the other hand, octanoyl L-phenylalaninol showed a marked lag in the development of its inhibitory action. The radioac-

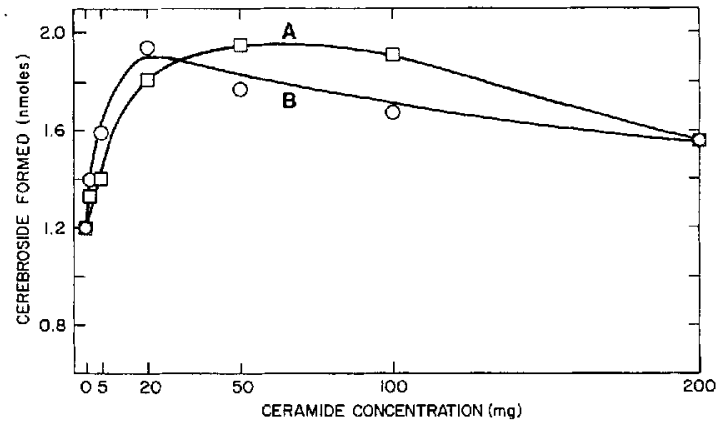

FIG. 1. Glucocerebroside formation by brain microsomes as a function of ceramide weight. Each incubation tube contained $0.5 \mathrm{mg}$ of microsomal powder and was incubated as in Methods with labelled UDP-Glc. Curve A: decanoyl sphingosine as glucose acceptor (M.W. 436). Curve B: nervonoyl sphingosine as acceptor (M.W. 648).

tive products were examined by TLC and were found to be only the usual cerebrosides, with no evidence for a galactosyl derivative of the inhibitor. Thus the lag period could not be attributed to gradual formation of a cerebroside analog which was a potent inhibitor. A similar study with the glucocerebroside synthesizing system and epoxydecanoyl norephedrine (Table 6) showed that the inhibitor gradually deactivated the enzyme; after 90 min there was little additional synthesis of cerebroside. This finding is consistent with the idea that the epoxy ring reacted covalently with the sugar transferase.

Several tests were made with substrates of different fatty acid chain lengths to make sure that our assays were carried out under proper (substrate-saturating) conditions. One such comparison (Fig. 1) with glucosetransferase and two somewhat different ceramides (10:0 and 24:1) showed that nervonoyl sphingosine was a better glucose acceptor at low concentrations but a poorer one at high concentrations. With both ceramides there was an optimal concentration of ceramide, probably due to a coating effect, since the lipids were applied to the dried microsomes by evaporation from benzene solution. No doubt it is difficult for the labelled UDP-Glc and cofactors to contact the enzyme when an excessively thick coating of ceramide has been applied. This effect also explains the inversion in activities seen in Fig. 1 at about $0.3 \mathrm{~mm}$ substrate since 24:1 ceramide must be somewhat less soluble in water than 10:0 ceramide.

\section{DISCUSSION}

Our finding that the galactosyltransferase does best with very short hydroxy ceramides (Table 1) could mean that such substrates do indeed exist and that such cerebrosides also exist. This suggestion is supported by examination of radioautographs made from TLC plates containing radioactive cerebrosides that were formed from hydroxy ceramides of 'natural' origin. That is, these ceramides were prepared chemically (CARTER et al., 1961) from assorted cerebrosides that 
had been isolated from beef nervous tissue. The radioautographs showed a small amount of radioactivity in the region of the very short hydroxy cerebrosides.

An alternative explanation is that the rates of galactose acceptance depend on the lipophile/hydrophile ratio of the ceramide. That is, a ceramide possessing a short fatty acid may be more readily brought into contact with the catalytic site of the enzyme, while the long chain ceramides tend to aggregate in the form of relatively large insoluble particles which cannot readily make contact with the catalytic site. Such an effect, if significant, would obscure the true preferences of the enzyme. An argument against the importance of physical differences in ceramides of different chain length comes from the data of Table 2: glucosyltransferase showed little chain length specificity despite the wide range of fatty acids. Moreover, $h 24: 0$ was a better acceptor than the shorter chain $h 18: 0$ ceramide in the case of galactosyl transfer.

With either explanation, there is still the question as to whether the galactosyltransferase truly uses hydroxy ceramides as its substrate in the intact animal. Attempts in several laboratories to find hydroxy ceramide in fresh brain have failed, although nonhydroxy ceramide was readily observed and Morell et al. (1970) have proposed that the rate-limiting step in hydroxy cerebroside synthesis is the hydroxylation reaction. This means that hydroxy ceramide is galactosylated as fast as it is formed, and thus does not accumulate to a detectable degree. This explanation is supported by the observation (UlLMAN \& RADIN, 1972) that brain contains enzymes which can acylate sphingosine with CoA esters of 2-hydroxy acids; these enzymes are specific for chain length of the fatty acid and are different from the enzymes which make nonhydroxy ceramides. That $\alpha$-hydroxylation is indeed a slow reaction is indicated by the studies with rat brain by Hoshi \& Kishimoto (1973). CARTER \& KANFER (1974) have attempted to detect hydroxy ceramides by injecting rats with labelled serine but failed to isolate detectable amounts of radioactivity. They consequently suggested that hydroxy ceramides are not normally formed or converted to cerebroside. However, such an interpretation requires the unsupported assumption that an undetectably small amount of an intermediate must nevertheless possess a detectable amount of radioactivity.

While we were disappointed that none of the galactosyltransferase inhibitors seemed to be unusually effective, it was encouraging to see that the glucosyltransferase inhibitors showed fairly good specificity with respect to the two enzymes. A disappointment with respect to specificity was the finding that amides of erythro-PAPD are good inhibitors of galactocerebrosidase (ARORA et al., 1973) yet are substrates for the two sugar transferases. Administration of such amides to animals might result in accumulation of galactocerebroside and its aromatic analog, as well as aromatic analogs of glucose-containing sphingoli- pids, such as gangliosides. The influence of such accumulation in rapidly dividing tissues, such as cancer cells, might be interesting to determine.

The enhanced formation of galactolipid when secondary amines were added to the incubations (Table 8 ) is particularly intriguing, since the amines might be acting as galactose acceptors. We have previously shown that $N$-hexyl galactosyl sphingosine is a fairly good inhibitor of galactocerebrosidase (ARORA et $a l ., 1973$ ) and it is likely that $N$-alkyl PAPD galactoside would also be a good inhibitor. Thus administration to an animal of $N$-alkyl PAPD might cause particularly enhanced accumulation of the abnormal galactocerebroside.

This study, like all searches for enzyme inhibitors, is in need of additional attempts. Leads for further syntheses can be seen from the observations recorded in this study and we are still synthesizing additional analogs, while commencing in vivo tests of some of the best inhibitors.

Our finding that hydroxyheptanoyl sphingosine was an excellent galactose acceptor raises the question as to whether we should shift to this as the normal substrate for assaying the galactosyltransferase of rat brain and for evaluating new ceramide analogs as inhibitors. The short chain ceramide is easier to prepare, especially since ethyl 2-bromo-heptanoate is now commercially available (Sapon Laboratories), and its $K_{m}$ is not much different than that of the mixed ceramides; thus competitive inhibitors could be detected readily. The high cost of the assays, due to the expensiveness of UDP-gal, would be appreciably diminished.

Acknowledgements- $-\mathrm{We}$ are indebted to CAROL SEIDL for assistance in carrying out the enzyme assays and radioautography, and to INEZ MASON for assistance in synthesizing the organic amides and amines. Dr. R. RaO VunNam prepared and characterized the decenoyl norephedrine epoxide in this laboratory.

\section{REFERENCES}

ARORA R. C., LIN Y.-N. \& RAdIN N. S. (1973) Arih. Biochem. Biophys. 156, 77-83.

Arora R. C. \& RadiN N. S. (1972a) J. Lipid Res. 13, 86-91.

Arora R. C. \& Radin N. S. (1972b) Biochim. Biophys. Acta 270, 254-259.

ARORA R. C. \& RADIN N. S. (1972c) Lipids 7, 56-59.

Basu S., Kaufman B. \& Roseman S. (1968) J. biol. Chem. 243, 5802-04.

Basu S., Schultz A. M., Basu M. \& Roseman S. (1971) J. biol. Chem. 246, 4272-79.

Benjamins J. A. \& AGRanoff B. W. (1969) J. Neurochem. 16, 513-527.

BRenker t A. \& RADIN N. S. (1972) Brain Res. 36, 183-193. CARTER T. P. \& KANFER J. (1974) J. Neurochem. 23, 589-594.

Carter H. E., Rothrus J. A. \& Gigg R. (1961) J. Lipid Res. 2, 228-234.

HajRa A. K., Bowen D. M., Kishimoto Y. \& Radin N. S. (1966) J. Lipid Res. 7, 379. 
Hoshi M. \& Kishimoto Y. (1973) J. biol Chem. 248, RADIN N. S. (1972) in Methods in Enzymology (GINSBURG 4123-4130.

Hyun J. C., Misra R. S., Greenblatt D. \& Radin N. S. (1975) Archs Biochem. Biophys. 166, 382-389.

LAPIDOT Y., RAPPOPORT S. \& WOLMAN Y. (1967) J. Lipid Res. 8, 142-145. V., ed.), Vol. 28, pp. 486-493. Academic Press, New York.

SHAH S. N. (1971) J. Neurochem. 18, 395-402.

Morell P., Costantino-Ceccarini E. \& Radin N. S. Shaw W. A., Harlan W. R. \& Bennett A. (1971) Analyt. Biochem. 43, 119-122.

(1970) Archs Biochem. Biophys. 141, 738-748.

Morell P. \& Radin N. S. (1969) Biochemistry 8, 506-512.

OESCh F., JERINA D. M. \& DALY J. (1971) Biochim. biophys. Acta 227, 685-691.

Ullman M. D. \& Radin N. S. (1972) Archs Biochem. Biophys. 152, 767-777. 